\title{
GENETIC CONTROL OF ENVIRONMENTALLY INDUCED CHANGES IN LINUM
}

\author{
A. DURRANT and J. N. TIMMIS \\ Department of Agricultural Botany, University College of Woles, Aberystwyth
}

Received 15.vi.72

\begin{abstract}
SUMMARY
Varieties of flax in which heritable changes can be induced by growing the plants in different environments are called plastic varieties. Large differences in plant weight and in amount of nuclear DNA can be induced in them. Other varieties are non-plastic either because they are genetically different or because their ancestral environments have stabilised them, or for both reasons. Crosses and backcrosses made between a plastic flax variety (Pl) and a non-plastic linseed variety $(R)$ were tested for plasticity by determining whether changes in amount of nuclear DNA are induced in them when grown in the specific inducing environments of nitrogen and phosphorus. Pl was found to contain a nuclear factor and a cytoplasmic factor both of which must be present for the plastic character to appear. $R$ contains neither of these factors but it has sites, in common with $\mathrm{Pl}$, at which changes in amount of nuclear DNA occur when the Pl nuclear and cytoplasmic factors are introduced. These genetic elements can be formally separated into regulator and structural genes. A varietal DNA difference between $\mathrm{Pl}$ and $\mathrm{R}$ of about 2.8 per cent. does not show a consistent pattern of inheritance in the different types of crosses, either because of the inducing treatments or because of other interactions between the genotypes.
\end{abstract}

\section{INTRODUCTION}

Heritable changes in plant weight can be induced in the flax variety Stormont Cirrus by growing the plants in a moderately heated greenhouse in soil compost to which are added different combinations of fertilisers in solution (Durrant, 1962a, 1971). The fertilisers are the specific inducing environments. Nitrogen, as ammonium sulphate, and phosphorus as triple-superphosphate applied to compost of low $p \mathrm{H}$, are used to induce respectively two extreme forms, a large genotroph (L) and a small genotroph (S). At the same time the two specific environments induce changes in amount of nuclear DNA, L having 16 per cent. more than S (Evans, Durrant and Rees, 1966; Evans, 1968). The divergence in amount of nuclear DNA in the treated plants occurs during the first 5 weeks of growth from sowing and is under normal conditions completed by the fifth week. Untreated plants of the original Stormont Cirrus variety are intermediate in plant weight and amount of nuclear DNA so that the specific inducing environments of nitrogen and phosphorus induce symmetrical changes.

The $\mathrm{L}$ and $\mathrm{S}$ genotrophs are stable in inheritance. Once induced, they breed true in plant weight in subsequent generations irrespective of fertilisers supplied and show no sign of reverting to the original type of plant. The induced changes in amount of nuclear DNA are also stable provided the plants are kept in a greenhouse for the first 5 weeks of growth each generation (Durrant and Jones, 1971). If the original Stormont Cirrus plants are grown under restricted pot conditions the induced plant weight changes on 
applying nitrogen and phosphorus may be small, but the induced changes in amount of nuclear DNA occur in the treated plants to the full 16 per cent. by the fifth week, falling to 7 per cent. in the next generation and approaches zero in the generation after.

Because heritable changes can be induced in Stormont Cirrus, plants of this variety are termed plastic $(\mathrm{Pl})$. The $\mathrm{L}$ and $\mathrm{S}$ genotrophs derived from it by environmental induction, in which heritable changes cannot normally be induced, are non-plastic. Lyral Prince is another variety which is plastic. A linseed variety, Royal, is non-plastic at least in the environments in which it has been tested. Royal may be non-plastic for the same reason that $\mathrm{L}$ and $\mathrm{S}$ stable genotrophs of Stormont Cirrus are nonplastic (Durrant, 1971), i.e. because of its ancestral environments. The environments in which Royal had been bred and multiplied prior to its use in experiments at Aberystwyth could already have stabilised it, with or without changes in plant weight or DNA. Equally, Royal may be non-plastic because it is genetically different from Pl, i.e. due to genetic factors of the orthodox kind, though they may at some time in the past also have been modified by the environment. These experiments on genetic control were aimed at finding evidence for genetic factors determining plasticity and do not tell of their origin.

To study the genetics of plasticity, crosses and backcrosses were made between Stormont Cirrus (Pl) and Royal (R). Instead of using the character plant weight, which is measured in the following generation at least 18 months after the inducing treatments were applied, the amount of nuclear DNA at the fifth week was assayed in the treated plants themselves. This has the additional advantage of avoiding unwanted genetic variation in the next generation due to segregation and recombination. The treated plants can also be grown in small pots in the greenhouse. Factors determining plasticity of plant weight may not be the same as those determining plasticity of amount of nuclear DNA but they probably have some genetic elements in common.

\section{Genotypes and Environments}

Stocks of plastic Stormont Cirrus (Pl) plants and non-plastic Royal (R) plants are maintained each year by growing the plants in a non-inducing environment. The plants are reared from sowing to maturity out of doors, several plants to a 7-inch pot containing a compost of soil, gravel and peat to which is added about one-third the usual amount of John Innes base fertiliser. Plants reared in this manner are not suitable for crossing, and in 1964 plants were grown separately in pots out of doors and later transplanted into the field, with a moderate amount of compound fertiliser, establishing in this way two separate sub-lines of $\mathrm{Pl}$, and two of Royal, which were carried on from year to year. Crosses and backcrosses were grown under similar conditions. Those plants to be tested for plasticity were reared in the greenhouse and received the specific inducing treatments. After DNA measurements had been made the treated plants were discarded; they were not used for crossing nor was seed taken from them, except on one occasion when assays were made on their progeny.

Reciprocal crosses were made between $\mathrm{Pl}$ and $\mathrm{R}$ in 1964 followed by successive backcrosses each year up to the fourth backcross in 1968. Pl and 
$\mathrm{R}$ were monitored over the years to make sure they had not changed in the non-inducing environments used. Some crosses were repeated such that $\mathrm{Pl}$ and R plants used for the fourth backcrosses were the same as those used for the first backcrosses and $F_{1}$ 's; these $F_{1}$ results were compared with those of $\mathrm{F}_{1}$ 's obtained using $\mathrm{Pl}$ and $\mathrm{R}$ plants which wereused for the first backcrosses of the series which led to the fourth backcrosses. Pl and R plants grown in 1965, 1967 and 1968 were compared. In none of these comparisons was there evidence that $\mathrm{Pl}$ or $\mathrm{R}$ had changed over the years.

For testing plasticity the plants were grown in the specific inducing environments of $\mathrm{N}$ and $\mathrm{P}$ in the greenhouse. For example if the $\mathrm{F}_{1}$ of $\mathrm{R} \times \mathrm{Pl}$ were to be tested for plasticity the procedure was to take two capsules each containing 10 seeds, and each obtained by crossing between different pairs of $\mathrm{Pl}$ and $\mathrm{R}$ plants using both of the $\mathrm{Pl}$ and $\mathrm{R}$ sub-lines. From each capsule, three seeds were sown in a 5 -inch $\mathrm{N}$ pot, three seeds in a 5 -inch $\mathrm{P}$ pot, and the remaining four were sown in the non-inducing environment for further crossing if required. One seedling was later removed from each $\mathrm{N}$ and $\mathrm{P}$ pot, usually at random, but occasionally an obviously ill-developed seedling was selectively removed. For the specific inducing environment of $\mathrm{N}$, the pot contained similar compost to that used for the non-inducing environment plus 1 per cent. solution of ammonium sulphate fertiliser applied to saturation at sowing with subsequent free drainage and watering. The specific inducing environment of $P$ was similar except that the soil used in the compost had a lower $p H$ and 1 per cent. solution of triple superphosphate fertiliser instead of ammonium sulphate. The seed was sown in early April and the pots kept in a moderately heated greenhouse. The shoot apices were removed at the fifth week and the amount of nuclear DNA measured by feulgen photometry according to the procedure described by Evans (1968).

\section{DNA MEASUREMENTS}

\section{(A) The first group of crossings; parents and $F_{1}$}

In $1968 \mathrm{Pl}$ and $\mathrm{R}$ plants from parents grown in 1967 and $\mathrm{F}_{\mathbf{1}}$ plants of $\mathrm{Pl} \times \mathrm{R}$ and $\mathrm{R} \times \mathrm{Pl}$ crosses in 1965 were tested for plasticity. The DNA values of the 24 plants, three plants of each of the eight genotype and treatment combinations, are given in table $1 a$. The $\mathrm{N}$ treated were analysed separately from the $\mathrm{P}$ treated plants, giving the split plot analysis of variance in table $1 b$. The $\mathrm{N}-\mathrm{P}$ difference, shown not significant in the table, becomes significant $(P<5$ per cent.) on a single tail test, since $N$ and $P$ induce overall DNA changes in the expected directions, or if the two errors which are not significantly different are combined. The genotypes (G) are significantly different because of the high $\mathrm{Pl} \times \mathrm{R}$ value. The important item is the $G \times T$ interaction which is highly significant, showing that there are differences among the parents and crosses in their response to the $N$ and $P$ treatments. There is a significant difference in amount of DNA of 8.5 per cent. between $\mathrm{N}$ and $\mathrm{P}$ treated $\mathrm{Pl}$ plants, but not in the treated $\mathrm{R}$ plants, confirming the plasticity of $\mathrm{Pl}$ and non-plasticity of $\mathrm{R}$. There is also a highly significant difference of 13.1 per cent. in $\mathrm{Pl} \times \mathrm{R}$ but not in $\mathrm{R} \times \mathrm{Pl}$, showing that there is either a cytoplasmic factor determining plasticity or there are strong maternal effects.

The full 16 per cent. difference is not obtained in Pl here, the probable reason being that the general and/or specific inducing environments were 
sun-optimal. The larger induced change in $\mathrm{Pl} \times \mathrm{R}$ compared with $\mathrm{Pl}$ may be due to the relatively slower growth of the PI plants as a consequence of the sub-optimal environments, particularly the $\mathrm{N}$ treated plants, and they may have been assayed a week or 10 days too soon. The high DNA value of $\mathrm{Pl} \times \mathrm{R}$ summed over the two treatments may result from interaction between the hybrid nucleus and cytoplasm or to asymmetric induction where the increase induced by $\mathrm{N}$ is greater than the decrease induced by $\mathrm{P}$, which could also have a nuclear/cytoplasmic basis or be due to the environmental conditions.

TABLE $1 a$

The first group of crossings. Amounts of nuclear DNA (arbitrary units) in parents and reciprocal $F_{1}$ 's

\begin{tabular}{|c|c|c|c|c|c|c|c|c|}
\hline & \multicolumn{3}{|c|}{ Replicates } & \multirow{2}{*}{\multicolumn{2}{|c|}{$\begin{array}{c}\text { Difference } \\
N-P\end{array}$}} & \multirow[b]{2}{*}{$\begin{array}{l}\text { Percentage } \\
\text { difference }\end{array}$} & \multirow[b]{2}{*}{ Mean } \\
\hline & & 1 & 2 & 3 & & & & \\
\hline $\mathrm{Pl}$ & $\left\{\begin{array}{l}N \\
P\end{array}\right.$ & $\begin{array}{l}19 \cdot 6 \\
19 \cdot 5\end{array}$ & $\begin{array}{l}20 \cdot 5 \\
18 \cdot 1\end{array}$ & $\begin{array}{l}20 \cdot 9 \\
18 \cdot 6\end{array}$ & $\begin{array}{l}61 \cdot 0 \\
56 \cdot 2\end{array}$ & $4 \cdot 8$ & 8.5 & $58 \cdot 6$ \\
\hline $\mathrm{Pl} \times \mathrm{R}$ & $\left\{\begin{array}{l}N \\
P\end{array}\right.$ & $\begin{array}{l}21 \cdot 6 \\
19 \cdot 6\end{array}$ & $\begin{array}{l}22 \cdot 3 \\
18 \cdot 5\end{array}$ & $\begin{array}{l}21 \cdot 6 \\
19 \cdot 8\end{array}$ & $\begin{array}{l}65 \cdot 5 \\
57 \cdot 9\end{array}$ & $7 \cdot 6$ & $13 \cdot 1$ & $61 \cdot 7$ \\
\hline $\mathrm{R} \times \mathrm{Pl}$ & $\left\{\begin{array}{l}N \\
P\end{array}\right.$ & $\begin{array}{l}19 \cdot 0 \\
18 \cdot 2\end{array}$ & $\begin{array}{l}18 \cdot 3 \\
20 \cdot 3\end{array}$ & $\begin{array}{l}19 \cdot 0 \\
20 \cdot 3\end{array}$ & $\begin{array}{l}56 \cdot 3 \\
58 \cdot 8\end{array}$ & $-2 \cdot 5$ & $-4 \cdot 4$ & 57.5 \\
\hline R & $\left\{\begin{array}{l}N \\
P\end{array}\right.$ & $\begin{array}{l}19 \cdot 2 \\
19 \cdot 5\end{array}$ & $\begin{array}{l}18 \cdot 6 \\
18 \cdot 7\end{array}$ & $\begin{array}{l}20 \cdot 1 \\
20 \cdot 5\end{array}$ & $\begin{array}{l}57 \cdot 9 \\
58 \cdot 7\end{array}$ & $-0 \cdot 8$ & $-1 \cdot 4$ & $58 \cdot 3$ \\
\hline
\end{tabular}

TABLE $1 b$

Analysis of variance of the first group of crossings

$\begin{array}{lrcc} & & \text { Mean } & \\ & \text { d.f. } & \text { square } & \text { V.R. } \\ \text { N-P difference }(T) & 1 & 3.450 & 5.77 \\ \text { Error }(a) & 4 & 0.598 & \\ \text { Parents and crosses }(G) & 3 & 2 \cdot 230 & 3.91^{*} \\ \text { G } \times \mathrm{T} & 3 & 3.721 & 6.51^{* *} \\ \text { Error }(b) & 12 & 0.570 & \end{array}$

Here and in other tables, $* \mathrm{P}>5$ per cent.; $* * \mathrm{P}>1$ per cent.; $* * * \mathrm{P}>0 \cdot 1$ per cent.

(B) Progeny of treated parents and $F_{1}$

The amounts of nuclear DNA were measured the following year in the progeny of the 24 treated parents and $F_{1}$ plants just described. The object was to check the results obtained from the treated plants by measuring the inherited effects, and to determine whether these were permanent. No $\mathrm{N}$ and $\mathrm{P}$ treatments were used. All the progeny were grown alike in pots containing normal compost with John Innes base fertiliser. The DNA values of the 24 progeny plants, one descended from each of the 24 plants previously assayed, are given in table $2 a$, and the analysis of variance (table $2 b$ ) shows that there is an overall significant difference in DNA due to the $\mathrm{N}$ and $\mathrm{P}$ treatments of the previous generation. There is again a highly significant $\mathrm{G} \times \mathrm{T}$ interaction which is obviously due to the presence of induced changes in the progeny of $\mathrm{Pl}$ and $\mathrm{PI} \times \mathrm{R}$ and their absence in the progeny of $\mathrm{R}$ and $\mathrm{R} \times \mathrm{PI}$.

These results confirm the plasticity of $\mathrm{Pl}$ and $\mathrm{Pl} \times \mathrm{R}$. The induced changes are inherited by the progeny but they have diminished in amount, 
on average from 10.8 to 6.5 per cent. They are therefore not permanent and they will probably approach zero in the next generation. It is possible that the full 16 per cent. induction was realised in the treated plants but they were assayed too soon in relation to their development in the conditions of the experiment, the $\mathrm{Pl}$ plants developing more slowly than $\mathrm{Pl} \times \mathrm{R}$. Summing over $\mathrm{N}$ and $\mathrm{P}$, the relatively high mean value for $\mathrm{Pl} \times \mathrm{R}$ in the treated plants has disappeared in their progeny and the $G$ item is not significant in table $2 b$, but a split down shows a highly significant difference between $\mathrm{Pl}$ and $\mathrm{Pl} \times \mathrm{R}$ on the one hand and $\mathrm{R}$ and $\mathrm{R} \times \mathrm{Pl}$ on the other, i.e. a matrilinear effect appearing in the $F_{2}$.

TABLE $2 a$

Amounts of nuclear DNA (arbitrary units) of the progeny, grown in a common environment, of parents and reciprocal $F_{1}$ 's of the first group of crosses which received the $\mathcal{N}$ and $P$ treatments as shown in table la

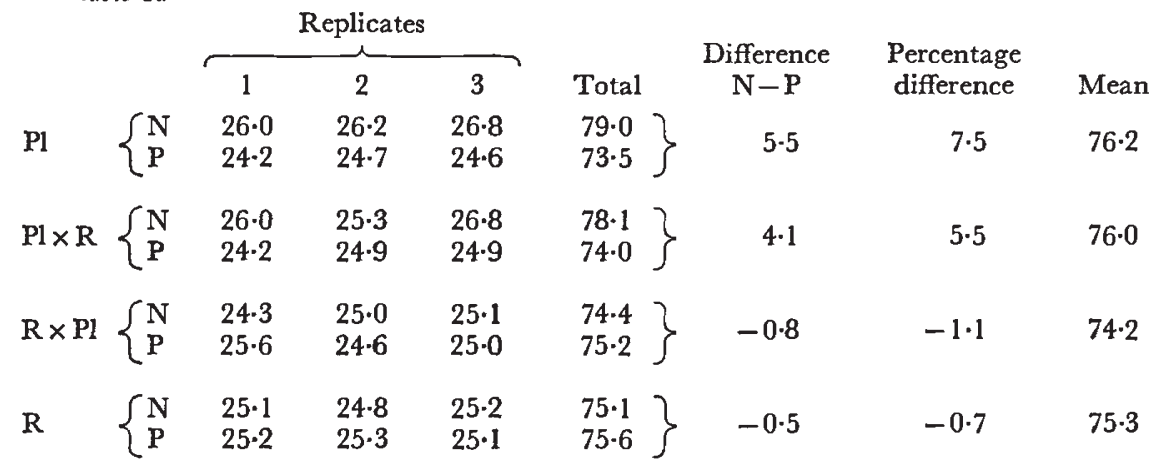

TABLE $2 b$

Analysis of variance of the progeny of the first group of crossings

\begin{tabular}{|c|c|c|c|}
\hline & d.f. & $\begin{array}{c}\text { Mean } \\
\text { square }\end{array}$ & V.R. \\
\hline $\begin{array}{l}\mathrm{N}-\mathrm{P} \text { difference transmitted from } \\
\text { previous generation }(\mathrm{T})\end{array}$ & 1 & $2 \cdot 801$ & $10 \cdot 61^{*}$ \\
\hline Error $(a)$ & 4 & 0.264 & \\
\hline Progeny of parents and crosses $(G)$ & 3 & 0.331 & $2 \cdot 19$ \\
\hline $\mathrm{G} \times \mathrm{T}$ & 3 & $1 \cdot 677$ & $11 \cdot 11 * * *$ \\
\hline Error $(b)$ & 12 & $0 \cdot 151$ & \\
\hline
\end{tabular}

(C) The second group of crosses; parents, $F_{1}$ 's and fourth backcrosses

Reciprocal $\mathrm{F}_{1}$ 's from crossings made in 1964 were backcrossed to both parents in 1965, and the backcrossing continued each year to give the fourth backcrosses in 1968 . Other crosses in 1968 provided a further set of reciprocal $F_{1}$ 's. In 1969 measurements were made on the plasticity of the fourth backcrosses, the $\mathrm{F}_{1}$ 's from the 1968 crosses, and $\mathrm{Pl}$ and $\mathrm{R}$ plants from parents grown in 1968. The design and experimental conditions for the induction of DNA differences with the $\mathrm{N}$ and $\mathrm{P}$ specific inducing environments were the same as in the previous group, except that within each of the three replicates there were 16 combinations of eight genotypes and two ( $N$ and $P$ ) treatments. The $\mathrm{N}$ and $\mathrm{P}$ treated plants in each replicate were assayed separately as before. 
Three genotypes in table $3 a$ have large induced changes in DNA. They are $\mathrm{Pl}, \mathrm{Pl} \times \mathrm{R}$ and $\mathrm{Pl}^{5} \times \mathrm{R}$, i.e. the fourth backcross of $\mathrm{Pl} \times \mathrm{R}$ on to $\mathrm{Pl}$ used as the female parent. In the other five the differences due to $\mathrm{N}$ and $\mathrm{P}$ are negligible. Table $3 b$ shows that this interaction $(\mathrm{G} \times \mathrm{T})$ is highly significant. Since $\mathrm{Pl} \times \mathrm{R}$ is plastic and $\mathrm{R} \times \mathrm{Pl}$ is not, $\mathrm{Pl}^{5} \times \mathrm{R}$ and $\mathrm{R}^{5} \times \mathrm{Pl}$ are expected to be plastic and non-plastic respectively. $\mathrm{R} \times \mathrm{Pl}^{5}$ is nonplastic although its nucleus is 97 per cent. $\mathrm{Pl} . \mathrm{Pl} \times \mathrm{R}^{5}$ is non-plastic although the $\mathrm{Pl}$ cytoplasmic line has been maintained over the backcross generations. Therefore both the $\mathrm{Pl}$ nucleus and the $\mathrm{Pl}$ cytoplasm is necessary for plasticity.

The amount of induced change is almost the same in $\mathrm{Pl}, \mathrm{Pl} \times \mathrm{R}$ and $\mathrm{Pl}^{5} \times \mathrm{R}$, about 12 per cent., which is again less than the 16 per cent. of full induction. There is no evidence that $\mathrm{Pl}$ or $\mathrm{R}$ has changed since the commencement of the crossing programme because the results of the parents and reciprocal $F_{1}$ 's are essentially the same as in the first group analysed.

There are significant differences between the genotypes summed over the two treatments. As in the previous group, $\mathrm{Pl}$ and $\mathrm{Pl} \times \mathrm{R}$ have higher DNA values than $R$ and $R \times P l$. This may again be a cytoplasmic effect or be due to asymmetric induction. Among the fourth backcrosses, the backcrosses to $\mathrm{Pl}$, i.e. $\mathrm{Pl}^{5} \times \mathrm{R}$ and $\mathrm{R} \times \mathrm{Pl}^{5}$, have $\mathrm{DNA}$ values approaching the $\mathrm{R}$ value, whereas backcrosses to $\mathrm{R}$, i.e. $\mathrm{R}^{5} \times \mathrm{Pl}$ and $\mathrm{Pl} \times \mathrm{R}^{5}$, have values equal to the $\mathrm{Pl}$ value. The difference between the two sets is significant. DNA measurements on untreated plants would help in the interpretation of these interactions.

(D) The third group of crossings; parents and first backcrosses

$\mathrm{Pl} \times \mathrm{R}$ is plastic, but $\mathrm{Pl} \times \mathrm{R}^{5}$ is not, and the change from one form to the other occurs in the intervening generations. Over this period the nucleus changes to nearly 100 per cent. $R$ constitution and there is also dilution of some cytoplasmic elements although not necessarily those determining plasticity. Ideally the sequence of backcrosses should be monitored to determine whether there is a gradual fall off in plasticity or whether it occurs immediately and totally after the $F_{1}$. As an alternative a single, but larger, experiment was done to measure the plasticity of the first backcross with the aim of picking up even a small decrease in plasticity from the maximum $\mathrm{Pl}$ and $\mathrm{Pl} \times \mathrm{R}$ values, should this occur. It was also supposed that in the first backcross it would be easier to pick up any genetic segregation of nuclear factors determining plasticity.

The two more informative backcrosses for the present purpose, $\mathrm{Pl}^{2} \times \mathrm{R}$ and $\mathrm{Pl} \times \mathrm{R}^{2}$, were assayed, together with $\mathrm{Pl}$ and $\mathrm{R}$. The number of plant replicates was increased to eight and the crosses from the two sets of sublines (ancestral replicates) were kept separate. Since the previous treatments may have given asymmetric induction with $\mathrm{P}$ inducing a smaller change than $\mathrm{N}$, and there was other evidence that the $p \mathrm{H}$ of the soil used for the $\mathrm{P}$ treatment was too high, soil from the same field of lower $p \mathrm{H}$ was used in the compost which in other respects was the same as before.

The DNA values of the 64 plants are given in table $4 a$. The analysis of variance (table $4 b$ ) repeats the pattern of previous analyses with significant differences between treatments $(\mathrm{T})$ and genotypes $(\mathrm{G})$, and highly significant interactions $(\mathrm{G} \times \mathrm{T})$ between them. The modified environments have induced considerably larger DNA changes than before in $\mathrm{Pl}$, approximately 18 per cent., but they have a negligible effect on $\mathrm{R}$. $\mathrm{Pl}^{2} \times \mathrm{R}$ has predictably 
induced changes comparable with $\mathrm{Pl}$ of 19 per cent. In $\mathrm{Pl} \times \mathrm{R}^{2}$ the induced change has dropped to 15 per cent. Evidently the change from a plastic to a non-plastic type is gradual over the backcross generations. If the induced change continued to drop by 4 per cent. in each succeeding backcross generation a value of 3 per cent. would be obtained in the fourth backcross. $\mathrm{Pl} \times \mathrm{R}^{5}$ in table $3 a$ has a difference of 1.7 per cent., equivalent to 2.7 per cent.

TABLE $3 a$

The second group of crossings. Amounts of nuclear DNA (arbitrary units) in parents, reciprocal $F_{1}$ 's and fourth backcrosses



after adjustment for the overall difference in amount of induction in the two sets. Although not significant this is close to the extrapolated 3 per cent.

The plant variances are given in table $4 a$. The greater variation between the $\mathrm{Pl}$ plants compared with the $\mathrm{R}$ plants is due to their greater developmental instability, a characteristic of the three $\mathrm{L}, \mathrm{S}$ and $\mathrm{Pl}$ genotrophs (Durrant, 1971). If this is inherited by the backcrosses and Pl and R contribute amounts proportional to the amount of chromosomal material present then the two backcrosses contain about the same amount of additional 
variation, i.e. $\mathrm{Pl}^{2} \times \mathrm{R}$ has 0.614 , and $\mathrm{Pl} \times \mathrm{R}^{2}$ has 0.523 , implying that both segregate for genetic factors determining plasticity, and there is no dominance. The plasticity of $\mathrm{Pl}^{2} \times \mathrm{R}$ has not dropped however compared with $\mathrm{Pl}$ and, excepting other unknown interactions, the larger variation in the backcrosses is as likely to be due to their greater developmental instability, or genetic instability of the kind shown by the Hh locus and plant weight in heterozygotes of L and S (Durrant, 1962b; Durrant and Nicholas, 1970).

TABLE $4 a$

The third group of crossings. Amounts of nuclear DNA (arbitrary units) in parents and first backcrosses. $I$ and $I I$ are the ancestral replicates. The variances are for between plants within treatments

\begin{tabular}{|c|c|c|c|c|c|c|c|}
\hline \multirow[b]{2}{*}{ Replicates } & \multicolumn{2}{|c|}{$\mathrm{Pl}$} & \multicolumn{2}{|c|}{$\mathrm{Pl}^{2} \times \mathrm{R}$} & \multicolumn{2}{|c|}{$\mathrm{Pl} \times \mathrm{R}^{2}$} & \multirow[b]{2}{*}{$\mathrm{N}$} \\
\hline & $\mathrm{N}$ & $\mathrm{P}$ & $\mathbf{N}$ & $\mathrm{P}$ & $\mathbf{N}$ & $\mathrm{P}$ & \\
\hline $\int 1$ & $28 \cdot 1$ & $23 \cdot 7$ & $29 \cdot 7$ & $23 \cdot 2$ & $26 \cdot 9$ & $23 \cdot 1$ & $25 \cdot 6$ \\
\hline 2 & $27 \cdot 2$ & $24 \cdot 3$ & $26 \cdot 5$ & $23 \cdot 6$ & $26 \cdot 7$ & $22 \cdot 9$ & $25 \cdot 4$ \\
\hline 3 & $26 \cdot 6$ & $24 \cdot 3$ & $27 \cdot 9$ & $23 \cdot 0$ & $24 \cdot 5$ & 23.7 & $25 \cdot 6$ \\
\hline 4 & $28 \cdot 4$ & $24 \cdot 1$ & $26 \cdot 2$ & $24 \cdot 6$ & $27 \cdot 4$ & $23 \cdot 2$ & $25 \cdot 0$ \\
\hline $\int 5$ & $29 \cdot 1$ & $23 \cdot 7$ & $28 \cdot 3$ & $22 \cdot 8$ & $27 \cdot 5$ & $24 \cdot 1$ & $25 \cdot 1$ \\
\hline 6 & $29 \cdot 0$ & $23 \cdot 5$ & $29 \cdot 7$ & $23 \cdot 4$ & 27.9 & $23 \cdot 2$ & $25 \cdot 1$ \\
\hline II & $27 \cdot 8$ & $22 \cdot 8$ & $27 \cdot 3$ & $23 \cdot 8$ & $28 \cdot 0$ & $24 \cdot 1$ & $25 \cdot 0$ \\
\hline 8 & $28 \cdot 0$ & $23 \cdot 5$ & $28 \cdot 0$ & $23 \cdot 3$ & $27 \cdot 0$ & $23 \cdot 5$ & $24 \cdot 9$ \\
\hline Total & $224 \cdot 2$ & $189 \cdot 9$ & $223 \cdot 6$ & $187 \cdot 7$ & $215 \cdot 9$ & $187 \cdot 7$ & $201 \cdot 7$ \\
\hline \multicolumn{8}{|l|}{ Difference } \\
\hline $\mathrm{N}-\mathrm{P}$ & \multicolumn{2}{|c|}{$34 \cdot 3$} & \multicolumn{2}{|c|}{$35 \cdot 9$} & \multicolumn{2}{|c|}{$28 \cdot 2$} & \\
\hline \multicolumn{8}{|l|}{ Percentage } \\
\hline difference & \multicolumn{2}{|c|}{$18 \cdot 1$} & \multicolumn{2}{|c|}{$19 \cdot 1$} & \multicolumn{2}{|c|}{$15 \cdot 0$} & \\
\hline Mean & \multicolumn{2}{|c|}{$207 \cdot 0$} & \multicolumn{2}{|c|}{$205 \cdot 6$} & \multicolumn{2}{|c|}{$202 \cdot 3$} & 1 \\
\hline \multirow[t]{9}{*}{ Variance } & \multicolumn{2}{|c|}{0.484} & \multicolumn{2}{|c|}{$1 \cdot 001$} & \multicolumn{2}{|c|}{$0 \cdot 716$} & \\
\hline & \multicolumn{7}{|c|}{ TABLE $4 b$} \\
\hline & \multicolumn{7}{|c|}{ Analysis of variance of the third group of crossings } \\
\hline & & & & d.f. & $\begin{array}{l}\text { Mea } \\
\text { squa }\end{array}$ & \multicolumn{2}{|r|}{ V.R. } \\
\hline & \multicolumn{2}{|c|}{$\mathrm{N}-\mathrm{P}$ difference $(\mathrm{T})$} & & 1 & $166 \cdot 4$ & \multicolumn{2}{|r|}{$104 \cdot 46 * *$} \\
\hline & \multicolumn{2}{|c|}{ Error $(a)$} & & 2 & $1 \cdot 5$ & & \multirow[b]{2}{*}{$5 \cdot 96 * *$} \\
\hline & \multicolumn{3}{|c|}{ Parents and backcrosses (G) } & 3 & $3 \cdot 1$ & & \\
\hline & \multicolumn{3}{|c|}{$\mathrm{G} \times \mathrm{T}$} & 3 & $12 \cdot 8$ & & $24 \cdot 18 * * *$ \\
\hline & Error $(b)$ & & & 54 & 0.5 & & \\
\hline
\end{tabular}

\section{Discussion}

Table 5 summarises the results of the tests on plasticity and shows the matrilinear nature of the inheritance, but there is also a gradual loss of plasticity in the $(\mathrm{PI} \times \mathrm{R})$ backcross lines to $\mathrm{R}$ male parents as the contribution of $\mathrm{R}$ to the nucleus increases and with the number of generations in which $\mathrm{R}$ genes are present. It is improbable that the matrilinear inheritance is due to maternal effects, i.e. seed size, carry-over of nutrients and hormones, for their effects would have to be particularly potent to make $\mathrm{Pl} \times \mathrm{R} \mathrm{F}_{1}$ completely plastic and $\mathrm{R} \times \mathrm{Pl} \mathrm{F}_{1}$ completely non-plastic. Furthermore one generation later the first backcross $\mathrm{PI} \times \mathrm{R}^{2}$ still has 80 per cent. plasticity. There must be factors in the cytoplasm of $\mathrm{Pl}$ which are necessary for the plastic character to appear. 
Among the fourth backcrosses, the plasticity of $\mathrm{P}^{5} \times \mathrm{R}$ and non-plasticity of $\mathrm{R}^{5} \times \mathrm{Pl}$ are predictable from the plasticity of $\mathrm{Pl} \times \mathrm{R}$ and non-plasticity of $\mathrm{R} \times \mathrm{Pl}$ in the $\mathrm{F}_{1}$. The $\mathrm{R} \times \mathrm{Pl}^{5}$ backcross shows that the $\mathrm{Pl}$ nucleus (or at least one that contains 97.5 per cent. of the $\mathrm{Pl}$ genes) is incapable by itself of conferring plasticity on the plant, nor is the Pl nucleus able to synthesise de nouveau the cytoplasmic factors necessary for plasticity which are normally present in the $\mathrm{Pl}$ cytoplasm but which are absent in the $\mathrm{R}$ cytoplasm. The non-plasticity of the $\mathrm{Pl} \times \mathrm{R}^{5}$ backcross has more than one interpretation. (i) The Pl cytoplasmic factor, or factors, is self-replicating and maintained independently of the nucleus throughout the backcross generations to $R$ male parents but it cannot confer plasticity on the plant in the absence of $\mathrm{Pl}$ nuclear factors. (ii) The cytoplasmic factor is self-replicating, but not autonomous, requiring the presence of $\mathrm{Pl}$ nuclear factors to multiply. In this case either the cytoplasmic factors may alone determine the plastic nature of the plant, being dependent upon the $\mathrm{Pl}$ nucleus for multiplication only, or it may require complementation by other Pl nuclear factors as well without which it could not determine plasticity.

TABLE 5

Parents, crosses and backcrosses classified according to their plastic character

$\begin{array}{lc}\text { Plastic } & \text { Non-Plastic } \\ \mathrm{Pl} & \mathrm{R} \\ \mathrm{Pl} \times \mathrm{R} & \mathrm{R} \times \mathrm{Pl} \\ \mathrm{Pl}^{2} \times \mathrm{R} & \mathrm{R} \times \mathrm{Pl}^{5} \\ \mathrm{Pl} \times \mathrm{R}^{2} \text { (80 per cent.) } & \mathrm{R}^{5} \times \mathrm{Pl}^{5} \\ \mathrm{Pl}^{5} \times \mathrm{R} & \mathrm{Pl} \times \mathrm{R}^{5}\end{array}$

In addition to these nuclear and cytoplasmic factors which must be present for changes in amount of nuclear DNA to be induced by the environments, there exists another class of factors in which the induced changes themselves occur. Pl plants must contain loci which are receptive to induced changes, but $R$ plants must possess loci which, when $R$ is crossed with $\mathrm{Pl}$, are equally receptive because the induced changes in DNA are of the same magnitude in $\mathrm{Pl} \times \mathrm{R}$ as in $\mathrm{Pl}$. An alternative and less tenable interpretation is that twice the amount of induced change occurs at loci on the $\mathrm{Pl}$ chromosomes in the hybrid nucleus compared with that in homozygous $\mathrm{Pl}$ nuclei to compensate for no induced changes in the $\mathrm{R}$ chromosomes. More probably $\mathrm{Pl}$ chromosomal factors may sensitise specific regions of the $\mathrm{R}$ chromosomes such that they become receptive to changes induced by the specific inducing environments. If the sensitising region of a $\mathrm{Pl}$ chromosome is homologous with the sensitised region on the $\mathrm{R}$ chromosome, changes resulting from their heterozygous state may be basically the same as those causing instability in Hh heterozygotes (Durrant and Nicholas, 1970; McLellan and Durrant, 1972) or paramutation in maize (Brink, 1960). Other situations which may have a similar basis are the partial reversions of the induced plant weight changes of $\mathrm{L}$ and $\mathrm{S}$ on outcrossing to some varieties but not to others (Durrant, 1972), and induced changes in plant weight appearing in the $\mathrm{F}_{1}$ and $\mathrm{F}_{2}$ of crossings between $\mathrm{L}$, or $\mathrm{S}$ (both normally stable) grown in inducing environments on the one hand and $\mathrm{PI}$ (i.e. the plastic type) grown in a non-inducing environment on the other (Durrant, 1971). In the present context the sensitising element in $\mathrm{Pl}$ could 
be the nuclear factor described above which is necessary for the plastic character to appear.

One of the features of the environmentally induced changes in plant weight and in amount of nuclear DNA is the dichotomy of the changes when the correct inducing environments are used. Ghanges in plant weight can be induced in equal amounts in a positive and negative direction from the $\mathrm{Pl}$ plant weight, giving the large (L) and small (S) stable types. Similarly the DNA values diverge. When $\mathrm{L}$ and $\mathrm{S}$ plants are grown at a lower temperature the DNA values converge towards the $\mathrm{Pl}$ value. The $\mathrm{Pl}$ nuclear factors therefore appear to be in a balanced state normally favoured in development to which induced changes in DNA tend to revert if, by supplying the right environment, or genetic background, they are allowed to do so. Summing over the $\mathrm{N}$ and $\mathrm{P}$ treatments, $\mathrm{R}$ has consistently less DNA than $\mathrm{Pl}$ in all four sets of analysis, but the difference is not large, averaging $2 \cdot 8$ per cent., and it may or may not be at other loci than those which undergo induced change, so that although $\mathrm{R}$ does not possess the nuclear and cytoplasmic factors necessary for induced changes it nevertheless contains an amount of DNA relatively close to that of PI nuclei in a balanced and potentially receptive state.

In the group of crosses containing the first backcrosses (table $4 a$ ) which has the largest amount of replication and where Pl has 3.9 per cent. more DNA than R, the mean amounts of nuclear DNA, obtained by summing in each case over the $\mathrm{N}$ and $\mathrm{P}$ treated plants, is proportional to the amount of $\mathrm{Pl}$ chromosomal material in $\mathrm{Pl}, \mathrm{Pl}^{2} \times \mathrm{R}, \mathrm{Pl} \times \mathrm{R}^{2}$ and $\mathrm{R}$. This comparison is probably valid because in this group the full 16 per cent. or more induction was obtained which is normally good evidence that the $\mathrm{N}$ and $\mathrm{P}$ treatments had induced changes symmetrically in plus and minus directions. This means that the induced changes in DNA are superimposed on the existing varietal DNA difference between $\mathrm{Pl}$ and $\mathrm{R}$, i.e. it is not cancelled out, suggesting perhaps that the varietal DNA difference is situated elsewhere on the chromosomes other than at the receptive sites. On the other hand, the reciprocal $F_{I}$ DNA values summed over the $N$ and $P$ treated plants have complete matrilinear inheritance, and the fourth backcrosses consistently and significantly have the non-recurrent parental values. DNA measurements on similar plants which had not been treated with $\mathrm{N}$ or $\mathrm{P}$ would help determine whether these relations are a reflection of the induced changes or whether they are due to other interactions between the two genotypes.

Plasticity, viewed here as a character determined by nuclear and cytoplasmic factors, can be interpreted as a regulatory system whose elements, in so far as they are identifiable at the level of the genetic analysis, interact in a manner suggestive of the operon first defined in Escherichia coli (Jacob and Monod, 1961). The site(s) at which the induced changes in amount of DNA occur is the structural gene; the chromosomal factor(s) is the regulator gene; the cytoplasmic factor(s) is, contains or produces the apo-inducer or apo-suppressor; and the inducing environments are, or lead to the synthesis, of, the co-inducer and co-suppressor. Normally the elements are in equilibrium but in inducing environments the system goes towards induction or suppression of DNA synthesis.

This is a formal comparison, for any regulating system must have regulator elements and structural elements. The induced changes occur 
over a period of 5 weeks, over many cell divisions, in contrast to the rapid build-up, or disappearance, within minutes of an induced enzyme in bacteria. The chromosomal factor cannot be the operator gene because it works in cis and trans to the structural gene, i.e. the same amount of DNA change apparently occurs in $\mathrm{R}$ and $\mathrm{Pl}$ chromosomes of $\mathrm{Pl} \times \mathrm{R}$. If there is a dominant structural gene which itself controls the amount of DNA production at another site the chromosomal factor could be the operator. Alternatively, it may determine the production or multiplication of the cytoplasmic factor. Changes in number of repeated sequences seem a more likely source of the changes in amount of nuclear DNA than polyteny. Since a general inducing environment promoting rapid healthy growth (Durrant, 1972) is essential for induction in flax, cell division may be essential for changes in number of gene sequences to occur. In a specific environment increasing the amount of DNA, the number of sequences increases at each cell division, and decreases at each cell division in an environment inducing less DNA, until a point is reached when no further changes can occur and the system becomes relatively stable. Induction of change in nuclear DNA is always associated with the induction of change in plant weight which is therefore probably under the control of the same regulatory elements.

\section{REFERENGES}

BRINK, R. A. 1960. Paramutation and chromosome organisation. Quart. Rev. Biol., 35, 120-137.

DURRANT, A. 1962a. The environmental induction of heritable change in Linum. Heredity, $17,27-61$.

DURRANT, A. 1962b. Induction, reversion and epitrophism of flax genotrophs. Nature, 204, 1302-1304.

DURRANT, A. 1971. Induction and growth of flax genotrophs. Heredity, 27, 277-298.

DURRANT, A. 1972. Studies on reversion of induced plant weight changes in flax by outcrossing. Heredity (in press).

DURRANT, A., AND JONES, T. W. A. 1971. Reversion of induced changes in amount of nuclear DNA in Linum. Heredity, 27, 431-439.

DURRANT, A., AND NICholas, D. B. 1970. An unstable gene in flax. Heredity, 25, 513-527.

EVANS, G. M. 1968. Nuclear changes in flax. Heredity, 23, 25-28.

EVANS, G. M., DURRANT, A., AND REES, H. 1966. Associated nuclear changes in the induction of flax genotrophs. Nature, 212, 697-699.

JACOB, F., AND MONOD, J. 1961. Genetic regulating mechanisms in the synthesis of proteins. 7. Mol. Biol., 3, 318-356.

MCLELLAN, J. C., AND DURRANT, A. 1972. Instability of Hh heterozygotes in flax genotrophs. Heredity (in press). 